point of quinaldic acid. was isolated from the urinary concentrates, and spectroscopic evidence for a derivative was compatible with $o$-aminobenzyl alcohol until comparison with authentic samples became possible. Numerous compounds with similar ultra-violet spectra could be differentiated using the eharacteristic shifts of the absorption maxima in three solvents: $0.05 \mathrm{~N}$ hydrochloric acid, $0.1 \mathrm{~N}$ ammonia and ethylether.

The reported biological relationship of substance $B$ ( $p$-phenetidine) can be explained by $(a)$ suppression of kynurenine excretion by some constituent of the antipyretic-analgesic mixtures containing phenacetine. Phenacetine itself fails to suppress the excretion of kynurenine. The second factor $(b)$ seems to be increased need of analgesics in patients on a meat-free diet. The occurrence of phenetidine in apparently healthy people may be an index of self-medication. (about 10 per cent).

Thanks are due to the National Cancer Institute of Canada for financial assistance, and to Drs. J. Patrick and K. Wiesner for samples of $o$-aminophenylmethylcarbinol and $o$-aminobenzylalcohol, respectively.

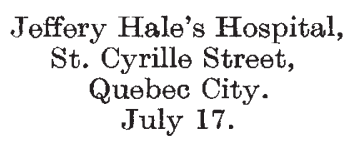

${ }^{1}$ Spaček, M., Nature, 172, 204 (1953).

\section{Chromosomal Biotypes in Emmer Wheat}

THE emmer wheat (Triticum dicoccum Schrank) and some of its varieties are known for their resistance to black rust, and the Indian emmer or khapli is extensively used in breeding rust-resistant varieties. It is usually grown in Central and Southern India and is commonly known as khapli wheat; botanically it is Triticum dicoccum Schrank var. farrum Bayle. According to Percival ${ }^{1}$, the Indian and Abyssinian emmers have had a common origin and both are allied to $T$. dicoccum Schrank var. ajar Percival.

In a collection of the Indian emmer wheats (khapli) at the Indian Agricultural Research Institute, New Delhi, two distinct races have been discovered differing from each other with respect to certain characters. These are shown in Table 1.

The two types also differ cytologically in having cither one or two pairs of $S A T$-chromosomes. As is well known, all the tetraploid wheats $(2 n=28)$, including $T$. dicoccum, have two pairs of $S A T$ chromosomes, whereas these types, provisionally called biotypes 1 and 2, breed true to their chromosome type, that is, the number of $S A T$-chromosomes (Fig. 1). So far as we know, such chromosomal biotypes have not been hitherto reported in emmer wheat and perhaps also not in other species of the

Table 1

\begin{tabular}{|l|c|c|}
\hline Characters & Biotype 1 & Biotype 2 \\
\hline Length of ear & $13 \cdot 0 \mathrm{~cm}$. & $9 \cdot 0 \mathrm{~cm}$. \\
Pollen size & $44.5-64 \cdot 7 \mu$ & $48 \cdot 0-63 \cdot 0 \mu$ \\
Pollen fertility & $79 \cdot 0$ per cent & $97 \cdot 4$ per cent \\
Grain-setting & 67.5 per cent & $90 \cdot 0$ per cent \\
Grain size & $9 \cdot 0 \mathrm{~mm}$. long & $8 \cdot 0 \mathrm{~mm}$. long \\
& $2.5 \mathrm{~mm}$. wide & $2 \cdot 3 \mathrm{~mm}$. wide \\
\hline
\end{tabular}

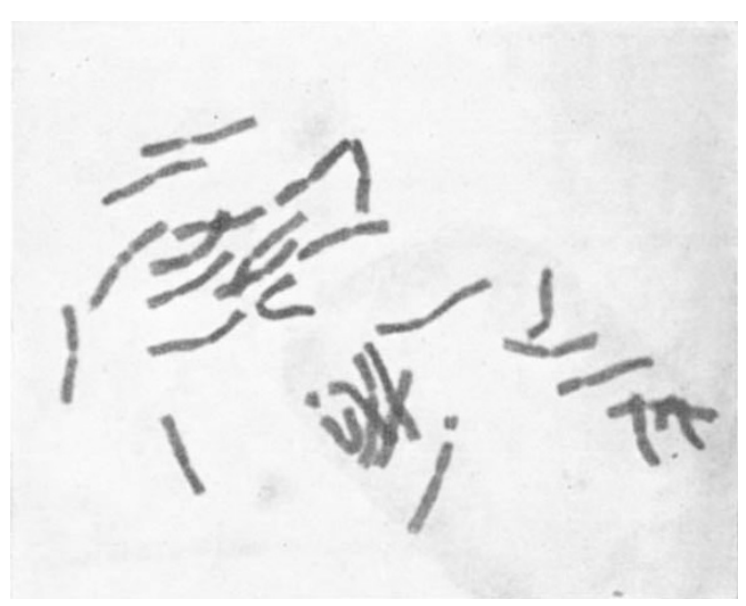

Fig. 1. T. dicoccum Schrank; $2 n=28$, with only one pair of SAT-chromosomes

genus Triticum. In barley, however, chromosomal biotypes have been recently reported by Hagberg and $\mathrm{rjio}$.

Fertility and grain-setting in interspecific crosses between khapli ( $T$. dicoccum) and bread wheat ( $T$. aestivum) have been variously reported by different workers. Haynes ${ }^{3}$ succeeded in getting fertile $F_{1}$ plants in reciprocal crosses between "Federation" and khapli. In crosses between "Garra", "Steinwedel" and khapli, Waterhouse ${ }^{4}$ obtained as high as 65 per cent of grain-setting. Pal ${ }^{5}$ has reported the $F_{1}$ hybrids between khapli and bread wheat to be "fairly highly fertile", while Bhatia" has recorded some seed-setting in similar crosses, but his $F_{1}$ plants did not grow to maturity. Recent observations at this Institute, however, have given almost the opposite results. Crosses made between khapli and bread wheat have given consistently highly sterile $F_{1}$ plants. This confirms the observations made earlier by Hayes and Stakman?. In view of the occurrence in Nature of two chromosomal biotypes of khapli, differing in their relative fertility, such variation in the fertility of $F_{1}$ hybrids, as observed by previous workers, is not only possible but also significant. Further studies on the behaviour of the hybrids of the two biotypes of khapli and types of Triticum aestivum in various combinations are likely to throw much light on: (i) the problem of relative fertility of the hybrids ; and (ii) the relative resistance of the hybrids to the different races of black-rust.

We thank Dr. B. P. Pal, director, and Dr. R. D. Asana, hoad of the Division of Botany, Indian Agricultural Research Institute, New Delhi, for giving the material and facilities to conduct the present investigation.

Division of Botany,

\section{P. N. BHADURI}

P. N. Ghosh

Indian Agricultural Research Institute, New Delhi 12. July 22.

1 Percival, J., "The Wheat Plant", 4.63 (Dutton and Co., New Xork, 1921).

Hagberg, A., and Tjio, J. H., Hereditas, 36, 487 (1950).

- Haynes, H. J. Phytopath., 19, 800 (1926).

- Waterhouse, W. L., Proc. Linn. Soc., N.S.W., 58, 99 (1933).

5 Pal, B. P., J. Ind. Bot. Soc., 27, 169 (1948).

- Bhatia, G. S., J. Genet., 35, 331 (1938).

Haves, H. K., and Stakman, E. C., Proc. 2nd Ann. Meet. Canad. Soc. Agron., 997 (1922). 